ORIGINALNI

ČLANAK

\title{
Correlation between non- -dominant foot placement variability with acceleration and agility performance in handball players
}

\author{
Povezanost varijabilnosti položaja stopala \\ nedominantne noge sa ubrzanjem i \\ agilnošću rukometaša
}

\author{
Hasan Ibrić, Fakultet za sport i turizam, Novi Sad \\ Jernej Rošker, Faculty of Health Sciences, Izola, Slovenia \\ Živa Majcen Rošker, Faculty of Sport, Ljubljana, Slovenia
}

ABSTRACT

Keywords:

Team sports

Speed,

Balance,

Stability,

Propulsive force
The horizontal acceleration and agility are both an essential part of sports performance in handball. The foot placement variability has been shown to vary between differences in speed and direction of running. However, no studies have considered the connection between the foot placement variability, forward acceleration and agility performance. In the present study, a proposed repetitive single leg countermovement drift test was analyzed as a measure of the foot placement variability and correlated with forward sprinting and agility performance in handball players. Twenty-three male handball players performed a series of 10 consecutive single leg countermovement jumps, $10 \mathrm{~m}$ forward acceleration sprint, a handball adapted T-agility test and a single leg countermovement jump test. Correlations between the drift area, T-agility test duration, acceleration performance are measured as well as the time used to accelerate at a $5 \mathrm{~m}$ and $10 \mathrm{~m}$ distance and the height of the single leg countermovement jump. The drift area for the non-dominant leg had high and significant negative correlations with the first $5 \mathrm{~m}$ of forward acceleration sprinting and a positive correlation with the T-agility test to the non-dominant side. The countermovement jump height had no significant correlation to any other parameters. This data indicates that the foot placement variability of the jumps performed on the non-dominant leg could be an indicator of the ability to control stability during short forward acceleration sprints and a quick change of direction. On the contrary, these correlations disappeared when the direction change was performed under reaction time conditions. 
Ibrić, H., Rošker, J., Majcen Rošker, Ž. - Non-dominant foot placement variability and performance in handball 2020. Fakultet za sport i turizam, Novi Sad, Tims.Acta 14, 31-39

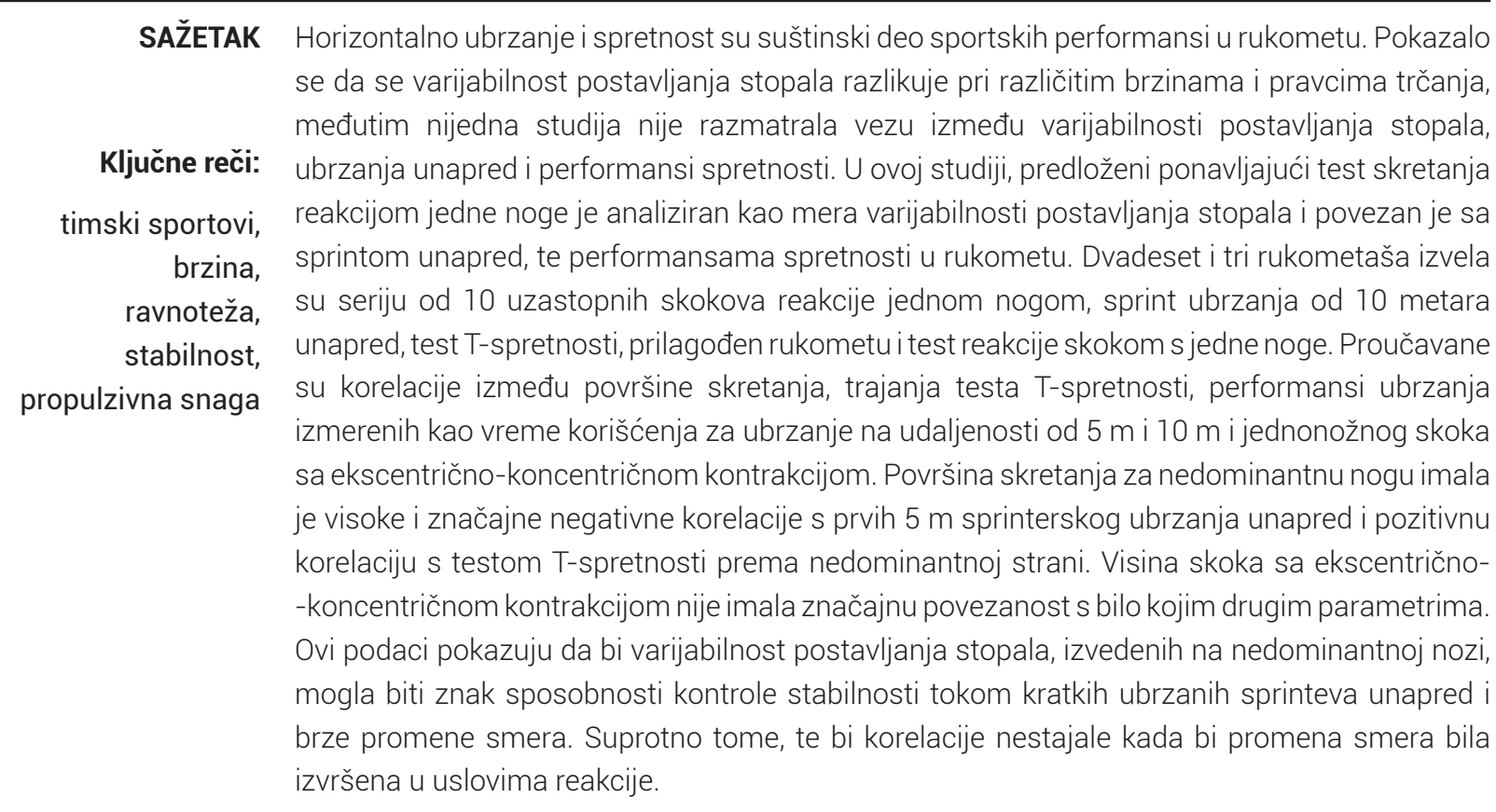

TIMS Acta (2020) 14, 31-39

\section{Introduction}

The horizontal acceleration is an essential part of the performance in team sports such as handball. Different factors are contributing to the horizontal acceleration, especially in forward sprinting performance. These studies varied from biomechanical characteristics or technique (Haugen, Thomas, McGhie, \& Ettema, 2019) to strength and power (Rumpf, Lockie, Cronin, \& Jalilvand, 2016). The distance acceleration is an important element in regards to sprinting biomechanics. It has been shown that shorter acceleration at a $10 \mathrm{~m}$ distance, depends more on strength and power of the lower limbs compared to sprints, where maximum speed can be achieved (Kawamori, Nosaka, \& Newton, 2013). This is also important for the acceleration and sprinting in handball where average acceleration distance is usually short, between 5 and 10 meters depending on the player's position and the action performed (Karcher \& Buchheit, 2014). Therefore, it is important to note that the first few steps are vital to gain a tactical advantage over an opponent.

It has been shown that the stride length, contact time and horizontal force are important contributors to the acceleration ability at distances for up to $10 \mathrm{~m}$ (Haugen et al., 2019). In addition, accelerations at shorter distances have been shown to produce higher demands on the strength and power production ability of the lower limb musculo-skeletal system (Sonderegger, Tschopp, \&
Taube, 2016). However, this cannot be directly transferred to the ability to quickly change the direction of movement. Moreover, the speed of forward movement has been shown to have no or moderate correlation to the speed of lateral movements (Swinton, Lloyd, Keogh, Agouris, \& Stewart, 2014; Tomáš, František, Lucia, \& Jaroslav, 2014) or agility measured with a T-test (Alemdaroğlu, 2012). This suggests that movement in different directions demands specific movement controlling strategies as suggested by more basic studies on motor control (Seethapathi \& Srinivasan, 2019). This is also partially supported by studies assessing the effects of training on horizontal or vertical power production ability in sprinting and agility performance. Although final conclusions cannot be drawn, a trend of direction of the specific training transferring to an on-field movement is suggested (Fitzpatrick, Cimadoro, \& Cleather, 2019).

It has been shown that the horizontal component of a push-off force vector directed towards the sprinting direction is an important determinant of a better sprinting performance (Haugen et al., 2019; Moir, Brimmer, Snyder, Connaboy, \& Lamont, 2018). The direction of the force vector orientation could be dependent on the placement of one's foot relative to the horizontal position of the center of gravity (Mehdizadeh, Arshi, \& Davids, 2014). Moreover, the foot placement has been shown to vary during running and thus influences the stability of running (Arshi, Mehdizadeh, \& Davids, 2015). However, no studies have systematically studied the role of the 
Ibrić, H., Rošker, J., Majcen Rošker, Ž. - Non-dominant foot placement variability and performance in handball 2020. Fakultet za sport i turizam, Novi Sad, Tims.Acta 14, 31-39

foot placement variability on acceleration and agility performance.

From the above-described perspective, it would be important to study the foot placement variability and correlate it to forward acceleration and agility performance. However, measuring forward acceleration at shorter distances demands the higher number of acceleration repetitions and could therefore lead to fatigue and consequently changes in the performance influencing foot placement variability. In addition, a small number of foot contacts performed with each individual leg during accelerations at short distances presents additional limitations to analyzing foot placement variability. Therefore, in this study, an attempt was to introduce a test of repeated single legged jumps to the study of the variability of foot contact positions. An increased foot contact variability could indicate the nature of controlling body stability during acceleration and movement direction changes. We propose a hypothesis that people with a superior acceleration ability and agility have a higher foot placement variability indicating more active control in running stability. In addition, the foot placement variability of the dominant and non-dominant leg will contribute differently to acceleration and agility performance.

\section{Methods}

In the present study twenty-three male handball players participated $(22,4 \pm 1,6$ years of age, $94,8 \pm 14,9 \mathrm{~kg}$ and $1,9 \pm 0,08 \mathrm{~m}$ ). All participants played in the EHF Champion league, had $4,1 \pm 0,2$ years of experience playing at the international level and had been involved in a systematic handball training regime for $10,7 \pm 2,3$ years. Participants played at different positions, but no goalkeepers were included. All the participants were required to sign an informed consent form. The study was performed according to the Declaration of Helsinki.

The exclusion criteria were: no reported locomotor system injuries in the last year, no neurological disease or vestibular pathology or any other disease/illnesses in the last 30 days. Instructions were given to the participants before the enrolment thus introducing them to the measurement tasks.

\section{Measures}

In the $10 \mathrm{~m}$ maximal forward acceleration task, intermediate times of first $5 \mathrm{~m}\left(\mathrm{t}_{1}\right)$, second $5 \mathrm{~m}\left(\mathrm{t}_{2}\right)$ and $10 \mathrm{~m}$ time $\left(\mathrm{t}_{10}\right)$ were measured using a photocell system (WittyManager 1.4.68., Microgate, Bolzano, Italy). Agility was measured using a modified T-agility test. Time needed to complete the agility test was measured for running to the dominant $\left(\mathrm{Tt}_{\mathrm{k}_{-} \mathrm{d}}\right.$ or $\left.\mathrm{Tt}_{\mathrm{u}_{\mathrm{C}} \mathrm{d}}\right)$ and non-dominant side $\left(\mathrm{Tt}_{\mathrm{k} \_n}\right.$ or $\left.\mathrm{Tt}_{\mathrm{u} \_n}\right)$ separately. The foot placement variability was assessed using a repetitive vertical jumps drift test. The analysis was performed using the Optogate software (Optogate Software 1.12.15.0, Microgate, Bolzano, Italy). Contact positions exceeding 2 standard deviations (SD) were excluded from the analysis. The most distal contact positions were used to interpolate a rectangular shape describing the area of the jumps drift area in $\mathrm{cm}^{2}$ (Area). In order to avoid the influence of differences in body height between subjects, the Area was normalized (NArea) as presented by the Equation 1 .

$$
\text { NArea }=\frac{\text { Area }}{R A^{2} \times 100}
$$

Equation 1: Presents the calculation of the Normalized area (NArea)

Where RA stands for the reference amplitude between the foot contact and the vertical projection of the center of body mass if the body was leaning at a $10^{\circ}$ angle. The RA was calculated as presented in Equation 2:

$$
R A=\left((B h \times 0.565) \times \cos 10^{\circ}\right)^{z}
$$

Equation 2: Presents the calculation of the normalized amplitude (NA)

Where Bh stands for the body height in meters and constant 0.565 is used to represent the relative height of the body's center of mass (Winter, 2009).

The single leg countermovement jump height $(\mathrm{H})$ was calculated from the flight time, measured by the previously described photocell system.

\section{Design and Procedures}

On the first day, measurements of a $10 \mathrm{~m}$ maximal forward acceleration and an adapted T-agility test were performed, followed by a single leg countermovement 
repetitive jumping drift test and a single legged countermovement jump test on the second day. On each day, the measurements were preceded by a standardized warm-up, consisting of 10 minutes of low intensity running, performing five strengthening exercises for the lower limbs, torso and upper extremities. This procedure was followed by short stretches of the major muscle groups.

On the first day, participants performed a $10 \mathrm{~m}$ forward acceleration sprint test on a standard handball court. Three pairs of photocells (Witty, Microgate, Bolzano, Italy) were positioned at a $5 \mathrm{~m}$ distance. Each subject performed three maximal accelerations on a $10 \mathrm{~m}$ distance, starting $0.5 \mathrm{~m}$ in front of the first pair of the photocells. After passing the last pair of photocells, the participants were able to stop slowly. Following each sprint, participant had a $3 \mathrm{~min}$ rest period in order to prevent fatigue. The repetition with the best time at a 10 $\mathrm{m}$ distance was taken for further analysis.

After measuring $10 \mathrm{~m}$ forward acceleration sprints, each participant rested for a period of $10 \mathrm{~min}$, which was followed by an adapted T-agility test. The test was adapted to meet the demands of the handball game dynamics as described by Spasic et al. (2015). Each participant started running $0.5 \mathrm{~m}$ behind the starting line, run forward for $3 \mathrm{~m}$, made a $90^{\circ}$ direction change and run laterally to one side ( $2.5 \mathrm{~m}$ distance), run laterally back to the middle and backwards to the starting line. The test was performed in two modes. In the first mode, the change of movement direction was known in advance $\left(T t_{k}\right)$ and in the second mode the change of the direction was unknown, indicated by the tester when the participant was one meter away from the point where the movement direction had to be changed $\left(\mathrm{Tt}_{\mathrm{u}}\right)$. In each condition, each participant performed three repetitions to the dominant (_d) and non-dominant (_n) side in a random order. The dominant side was defined as the side of the leg preferably used by the subject to perform a single leg jump. The best time for each direction was taken for further analysis.
On the second day, beforementioned drift test was measured following a standardized warm-up protocol described above. In this test, the subjects had to perform 10 consecutive single legged countermovement jumps with each leg separately and their hands positioned on their hips. The participants were instructed to jump as high as possible while jumping on the predefined spot on the floor, marked by a cross $5 \mathrm{~cm}$ by $5 \mathrm{~cm}$. During the test, each participant had to look at a predefined spot positioned at a standing eye-height at a $3 \mathrm{~m}$ distance. The anterior-posterior and medial-lateral linear difference in position of the contacts between consecutive jumps was measured by a photocell system (Optogate, Microgate, Bolzano, Italy) set in a two-dimensional setup. Each participant performed one set of jumps for each leg.

\section{Statistical Analysis}

Statistical analysis was performed using the SPSS software (SPSS statistics 23, IBM, New York, United States). The correlations between different $10 \mathrm{~m}$ acceleration times and T-agility test times with other parameter were calculated using the Pearson correlation coefficient $(r)$. The $r$ was treated as no correlation for $r<$ .3 , small correlation for $.3<r<.5$, medium correlation for $.5<r<.7$ and high correlation for $r>.7$. The statistical significance $(p)$ was set at $p<.05$.

\section{Results}

Results of the correlation analysis are presented in Table 1. High and statistically significant correlations were observed between Area ${ }_{-n}$ and $t_{1}$ or $\mathrm{Tt}_{\mathrm{k}_{-} \mathrm{n}}$. The Height of the countermovement jump had no correlation to any of the parameters describing $10 \mathrm{~m}$ maximal sprint or T- agility test. High and statistically significant correlations were also observed between $t_{1}$ and $t_{2}$ or $\mathrm{Tt}_{\mathrm{k}_{\_} \text {n }}$. 
Ibrić, H., Rošker, J., Majcen Rošker, Ž. - Non-dominant foot placement variability and performance in handball 2020. Fakultet za sport i turizam, Novi Sad, Tims.Acta 14, 31-39

Table 1. Correlations between $10 \mathrm{~m}$ forward acceleration sprint, $\mathrm{t}$-test and single leg countermovement jump parameters

\section{Parameter}

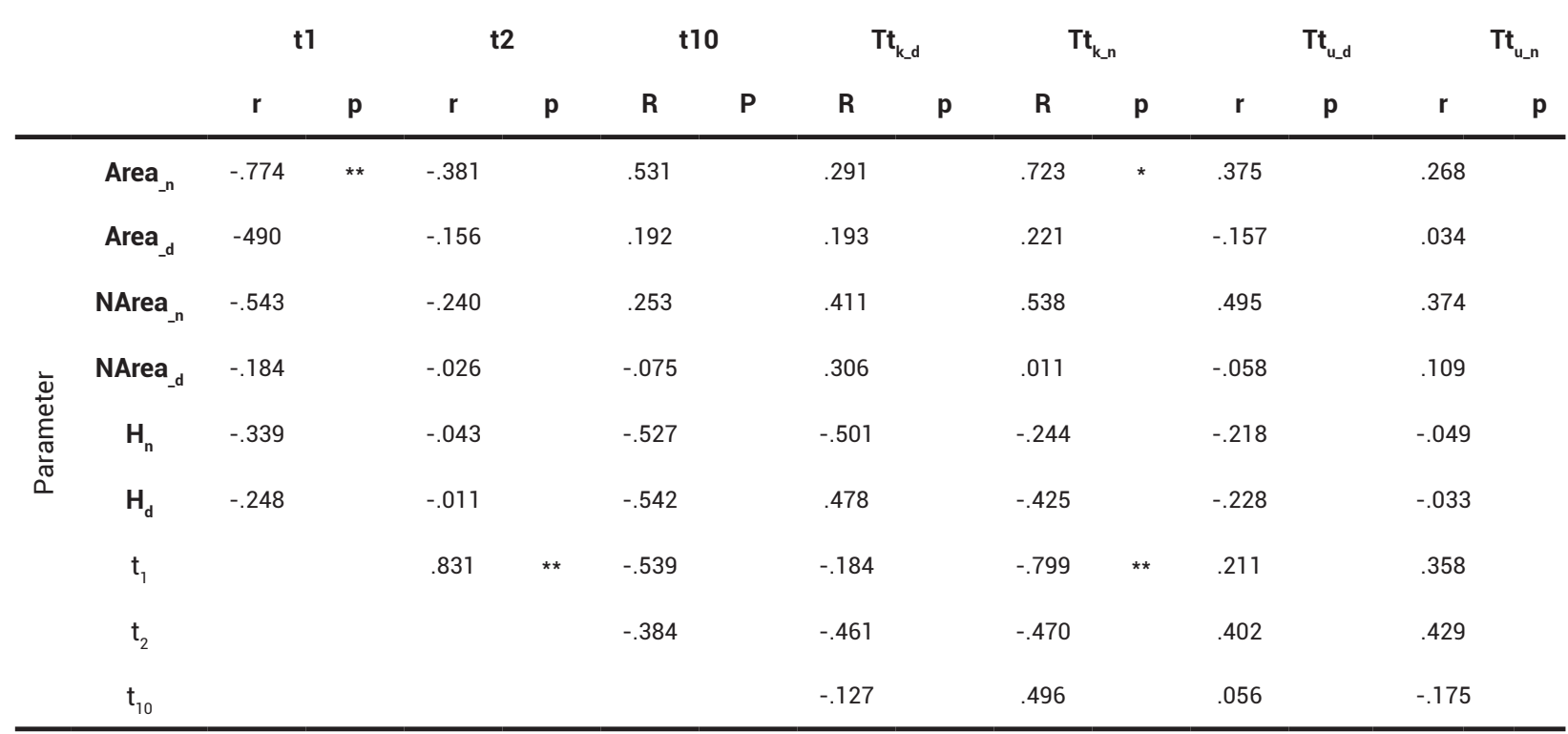

Area $_{-\mathrm{n}}$ - a drift area of the jumps on the non-dominant leg;

Area $_{-\mathrm{d}}$ - a drift area of the jumps on the dominant leg;

NArea ${ }_{n}$ - a normalized drift area of the jumps on the non-dominant leg;

NArea $_{-}$- a normalized drift area of the jumps on the dominant leg;

$\mathbf{H}_{n}-$ the height of the countermovement jump performed on the non-dominant leg;

$\mathbf{H}_{\mathrm{d}}$ - the height of the countermovement jump performed on the dominant leg;

$\mathbf{t}_{1}$ - the time of the first $5 \mathrm{~m}$ of the $10 \mathrm{~m}$ maximal forward acceleration sprint;

$\mathbf{t}_{2}$ - the time of the second $5 \mathrm{~m}$ of the $10 \mathrm{~m}$ maximal forward acceleration sprint;

$\mathbf{t}_{10}$ - the time of the $10 \mathrm{~m}$ maximal forward acceleration sprint;

$\mathrm{Tt}_{\mathrm{k} \_\mathrm{d}}$ - the time of the T-agility test with the known change of direction to the dominant side;

$\mathrm{Tt}_{\mathrm{u}_{-\mathrm{d}}}$ - the time of the T-agility test with the unknown change of direction to the dominant side;

$\mathrm{Tt}_{\mathrm{k} \_\mathrm{n}}$ - the time of the T-agility test with the known change of direction to the non-dominant side;

$\mathrm{Tt}_{\mathrm{u} \_\mathrm{n}}$ - the time of the T-agility test with the un-known change of direction to the non-dominant side;

p - statistical significance. 
Ibrić, H., Rošker, J., Majcen Rošker, Ž. - Non-dominant foot placement variability and performance in handball 2020. Fakultet za sport i turizam, Novi Sad, Tims.Acta 14, 31-39

Scatter plots for the statistically significant pairs of correlations are presented in Figure 1.

A

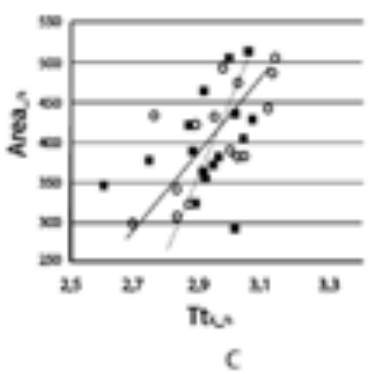

B

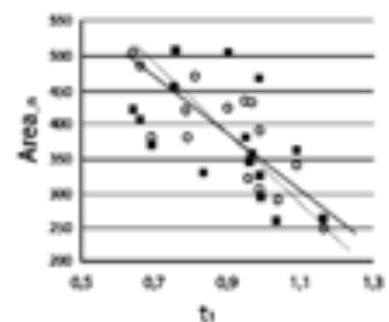

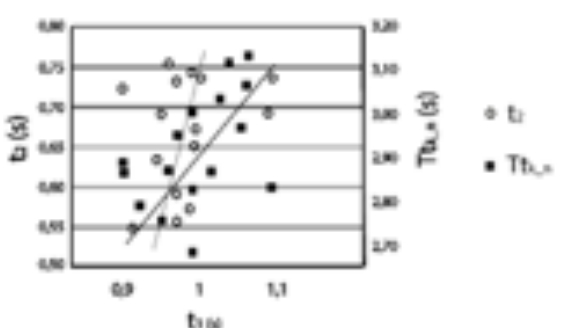

Figure 1. Scatter-plots for the statistically significant correlation pairs

Area $_{{ }_{n}}$ - a drift area of the jumps on the non-dominant leg;

$\mathbf{t}_{1}$ - the time in the first $5 \mathrm{~m}$ of the $10 \mathrm{~m}$ maximal forward acceleration sprint; $\mathrm{t}_{2}$ - the time in the second $5 \mathrm{~m}$ of the $10 \mathrm{~m}$ maximal forward acceleration sprint; $\mathrm{Tt}_{\mathrm{k}-\mathrm{n}}$ - the time of the T-test with the known change of direction to the non-dominant side

\section{Discussion}

In the present study, the foot placement variability measured with a drift during the repetitive single leg countermovement jumps proved to have an important correlation to sprinting and agility performance. The correlation between the Area ${ }_{-n}$ and $t_{1}$ proved to be negative. On the contrary, correlation between the Area and $\mathrm{Ttk}_{\mathrm{n}}$ was positive. Interestingly, no significant correlations were observed between the maximal single leg countermovement jumping height and $t_{1}$ or any $\mathrm{Tt}$ times.

As suggested by our hypothesis, the correlation between Area ${ }_{n}$ and $t_{1}$ was high and negative. Our results indicate that increased area during the drift test performed with the non-dominant leg is associated with better performance at a $5 \mathrm{~m}$ forward acceleration sprint task, but not with longer accelerations, shown by absent correlations with $t_{2}$ and $t_{10}$. One of the rationales behind our hypothesis is based on the possible negative effect of the increased lateral vector component of the propulsive force vector during the push-off, which could result in an increased foot placement variability. As suggested by Morin et al. (2015), the ability to produce a higher horizontal component of the ground reaction force impulse significantly affects acceleration in sprints up to
$40 \mathrm{~m}$. However, no studies have focused on sagittal and frontal plane components of the ground reaction force impulse separately (Edouard et al., 2018; Morin, Gimenez et al., 2015). It could be speculated that the increased lateral component could be detrimental as it changes the orientation of the horizontal propulsion force vector and consequently decreases its component that is oriented to the direction of running. Although propulsive vector orientation and size were not measured in this study, the results suggest that the increased foot placement variability is beneficial for a better performance in short forward acceleration sprints. This implies that the foot placement variability cannot be directly related to common propulsive force vector. It could be suggested, that it is to a larger extent connected to a constant demand to preserve stability of the body's center of mass trajectory during running. This is the primary variable that needs to be controlled during forward running at high speed (Arshi, Mehdizadeh, \& Davids, 2015).

In addition, a human body is a complex multicomponent system. During a push-off, the muscular system of the trunk and the lower limbs must produce a coordinated and explosive contraction. This has to be accomplished with a locomotor system characterized by multiple degrees of freedom. For example, each joint of the lower limbs is 
able to move in more than one axis. This is controlled by multiple muscles. As suggested by the more recent motor control theory such as dynamical systems theory and theory of muscle synergies, muscles connect to muscle groups or muscle modes with the goal of effectively executing the task, enabling adaptability and the stability of the performance (Latash, 2010). The research using this concept has shown that simple movements can consist of more than one muscle mode. Such example is a simple forward and backward body oscillation task during an upright stance where two modes are concerned with puling the body forward or backwards respectively and the third mode is concerned with holding the mediallateral stability (Danna-Dos-Santos, Slomka, Zatsiorsky, \& Latash, 2007). Studies of running indicate that similar strategies are used to control body's stability during forward or lateral running where anterior-posterior and medial-lateral stability are controlled differently (Arshi, Mehdizadeh, \& Davids, 2015). This would suggest that medial-lateral stability during running is not necessarily connected to the forward propulsion. In addition, the foot placement variability has been hypothesized to be larger than the movement variability of the more proximal body parts during running which confirms its importance in controlling the proximal stability of the body (Mehdizadeh, Arshi, \& Davids, 2014). On the other hand, studies analyzing isolated explosive tasks of the lower limbs have shown that muscle synergies must be abruptly destroyed in order to achieve an explosive increase in force (Sarabon, Markovic, Mikulic, \& Latash, 2013) which could be the case in the push-off phase during acceleration. Considering the above theories, one could speculate that this abrupt falling apart of propulsive muscle synergies due to push-off, might also affect medial-lateral stabilization synergy. This fine-tuned control of medial-lateral stability synergy has not been studied up to date, but could provide an interesting insight that might shed a light on the nature of coordinating different muscle synergies during forward acceleration and the change of movement direction.

However, the above proved was not in the case of the agility task, where the smaller Area was positively correlated to a shorter time in a T-agility test. During this test the movement and push-off must be performed in various directions. The "stabilizing" medial-lateral synergy might start overtaking the role of lateral propulsive and deceleration synergy in addition to taking care of the anterior-posterior stability. These observations are in line with the relatively low or absent correlations between the forward acceleration and lateral movement during a T-agility test observed in this study. Therefore, it can be suggested that these movements depend on different controlling mechanisms.

An important perspective that could help to understand the mismatch between the forward sprinting and the agility is the fact that this study only measured handball players. The game of handball demands constant adaptations in running direction. It could be argued that the handball training is more efficient in developing quick direction changes and lateral movement as it is in developing forward acceleration. From this perspective, less precise control of the medial-lateral stability during forward running might be advantageous. Stability represents the ability of a system to return to the previous position or to return to the desired trajectory of the movement (Reeves, Narendra, \& Cholewicki, 2007). However, changing the direction of the movement demands a sudden loss of stability in order to regain a new stable state. In case of the agility in handball, less precise medial-lateral control might enable more abrupt changes in movement direction. To test these hypothesis future studies should assess athletes where lateral movements are not systematically developed and where sprinting is performed only in forward directions such as in track and field.

Interestingly, the above described connections between the Area and forward or lateral movement times were seen only for the non-dominant leg. Exell et al. (2017) reported that lower limb strength asymmetries do not affect sprinting performance and are most probably task specific. In addition, running asymmetries were not shown to be related to injuries in sprinters (Haugen, Danielsen, McGhie, Sandbakk, \&Ettema, 2018). However, the classical approach towards understanding muscle asymmetries focuses on strength and power asymmetries. These studies usually do not consider the special adaptations that the lower limbs might develop (Galamb et al., 2018; Promsri, Haid, \& Federolf, 2018; Yamaguchi, Milosevic, Sasaki, \& Nakazawa, 2019). Simple examples of the leg specificity can be shown by developing a preferred leg for performing single leg jumps, single leg balance tasks or precision oriented manipulative tasks such as handling a football. As suggested by the work of Promsri et al. (2018) and Promsri et al. (2019) the specific movement control strategies between the two legs differ, especially in the control of the inter-joint coordination and the dynamics of movement. This is promising as it could enable better understanding of the specific function of each lower limb 
Ibrić, H., Rošker, J., Majcen Rošker, Ž. - Non-dominant foot placement variability and performance in handball 2020. Fakultet za sport i turizam, Novi Sad, Tims.Acta 14, 31-39

and the identification of asymmetry types important for running and the agility performance.

Interestingly, no correlations between a single leg vertical jump height, $10 \mathrm{~m}$ forward acceleration and T-agility test were observed. This is somehow surprising as it is not in line with the general guidelines presented in the literature (Sonderegger, Tschopp, \& Taube, 2016). In addition, no correlations were found between the foot contact position variability and the single leg vertical jump height. Our data indicates that the ability to control foot contact position variability is not necessarily linked to the propulsive force production and could be a measure of mechanisms responsible for controlling stability of the moving body. This suggests that forward acceleration is also dependent on the ability to preserve stability of the athlete's body rather than on the power production capacity.

As could be expected, the T-agility test where the change of movement direction was performed in a nonanticipatory manner had no correlation with any of the observed parameters. This is in line with the literature stating that an important aspect of agility is also the ability to perceive the in-game situation and react accordingly (Paul, Gabbett, \& Nassis, 2016). This study indicates that, although the motor control perspective of changing direction of movement is important and should be studied further, the cognitive decision training represents an important, but separate entity. It would be interesting to better understand how these two properties interact together and affect sports performance as well as the injury prevention.

The present study presented important limitations such as the small sample size, possibly effecting the correlation assessment. Future studies should use a bigger sample size in order to gain higher statistical power. In addition, comparisons to athletes from other sports disciplines and a control group should also be made. Another important limitation was the nature of the repetitive vertical jumping test, which did not demand the production of horizontal push-off forces as it is the case in sprinting and agility tests used in this study. This discrepancy could have influenced the results and limited the applicability of the data. In the future, consecutive horizontal jumps should be studied in order to enable more specific testing and comparisons.

\section{STATEMENT}

In their statements, the authors confirmed the absence of any conflict of interest.

\section{REFERENCES}

Alemdaroğlu, U. (2012). The relationship between muscle strength, anaerobic performance, agility, sprint ability and vertical jump performance in professional basketball players. Journal of Human Kinetics, 31, 149-158.

Arshi, A. R., Mehdizadeh, S., \& Davids, K. (2015). Quantifying foot placement variability and dynamic stability of movement to assess control mechanisms during forward and lateral running. Journal of Biomechanics, 48(15), 4020-4025.

Danna-Dos-Santos, A., Slomka, K., Zatsiorsky, V. M., \& Latash, M. L. (2007). Muscle modes and synergies during voluntary body sway. Experimental Brain Research, 179(4), 533-550.

Edouard, P., Mendiguchia, J., Lahti, J., Arnal, P. J., Gimenez, P., Jiménez-Reyes, P., Brughelli, M., Samozino, P., \& Morin, J.B. (2018). Sprint Acceleration Mechanics in Fatigue Conditions: Compensatory Role of Gluteal Muscles in Horizontal Force Production and Potential Protection of Hamstring Muscles. Frontiers in Physiology, 9, 1706.

Exell, T., Irwin, G., Gittoes, M., \& Kerwin, D. (2017). Strength and performance asymmetry during maximal velocity sprint running. Scandinavian Journal of Medicine \& Science in Sports, 27(11), 1273-1282.

Fitzpatrick, D. A., Cimadoro, G., \& Cleather, D. J. (2019). The Magical Horizontal Force Muscle? A Preliminary Study Examining the „Force-Vector" Theory. Sports (Basel, Switzerland), 7(2).

Galamb, K., Szilágyi, B., Magyar, O. M., Hortobágyi, T., Nagatomi, R., Váczi, M., \& Négyesi, J. (2018). Effects of side-dominance on knee joint proprioceptive target-matching asymmetries. Physiology International, 105(3), 257-265.

Haugen, T., Danielsen, J., McGhie, D., Sandbakk, Ø., \& Ettema, G. (2018). Kinematic stride cycle asymmetry is not associated with sprint performance and injury prevalence in athletic sprinters. Scandinavian Journal of Medicine \& Science in Sports, 28(3), 1001-1008.

Haugen, Thomas, McGhie, D., \& Ettema, G. (2019). Sprint running: From fundamental mechanics to practice-a review. European Journal of Applied Physiology, 119(6), 1273-1287.

Karcher, C., \& Buchheit, M. (2014). On-court demands of elite handball, with special reference to playing positions. Sports Medicine (Auckland, N.Z.), 44(6), 797-814.

Kawamori, N., Nosaka, K., \& Newton, R. U. (2013). Relationships between ground reaction impulse and sprint acceleration performance in team sport athletes. Journal of Strength and Conditioning Research, 27(3), 568-573.

Latash, M. L. (2010). Motor synergies and the equilibrium-point hypothesis. Motor Control, 14(3), 294-322. 
Ibrić, H., Rošker, J., Majcen Rošker, Ž. - Non-dominant foot placement variability and performance in handball 2020. Fakultet za sport i turizam, Novi Sad, Tims.Acta 14, 31-39

Moir, G. L., Brimmer, S. M., Snyder, B. W., Connaboy, C., \& Lamont, H. S (2018). Mechanical Limitations to Sprinting and Biomechanical Solutions: A Constraints-Led Framework for the Incorporation of Resistance Training to Develop Sprinting Speed. Strength \& Conditioning Journal, 40(1), 47.

Mehdizadeh, S., Arshi, A. R., \& Davids, K. (2014). Quantification of stability in an agility drill using linear and nonlinear measures of variability. Acta of Bioengineering and Biomechanics, 16(3), 59-67.

Morin, J.-B., Gimenez, P., Edouard, P., Arnal, P., Jiménez-Reyes, P., Samozino, P., Brughelli, M., \& Mendiguchia, J. (2015). Sprint Acceleration Mechanics: The Major Role of Hamstrings in Horizontal Force Production. Frontiers in Physiology, 6, 404.

Morin, J.-B., Slawinski, J., Dorel, S., de Villareal, E. S., Couturier, A., Samozino, P., Brughelli, M., \& Rabita, G. (2015). Acceleration capability in elite sprinters and ground impulse: Push more, brake less? Journal of Biomechanics, 48(12), 3149-3154.

Naylor, J., \& Greig, M. (2015). A hierarchical model of factors influencing a battery of agility tests. The Journal of Sports Medicine and Physical Fitness, 55(11), 1329-1335.

Paul, D. J., Gabbett, T. J., \& Nassis, G. P. (2016). Agility in Team Sports: Testing, Training and Factors Affecting Performance. Sports Medicine (Auckland, N.Z.), 46(3), 421-442.

Promsri, A., Haid, T., \& Federolf, P. (2018). How does lower limb dominance influence postural control movements during single leg stance? Human Movement Science, 58, 165-174.

Promsri, A., Longo, A., Haid, T., Doix, A.-C. M., \& Federolf, P. (2019). Leg Dominance as a Risk Factor for Lower-Limb Injuries in Downhill Skiers-A Pilot Study into Possible Mechanisms. International Journal of Environmental Research and Public Health, 16(18).

Reeves, N. P., Narendra, K. S., \& Cholewicki, J. (2007). Spine stability: The six blind men and the elephant. Clinical Biomechanics (Bristol, Avon), 22(3), 266-274.

Rumpf, M. C., Lockie, R. G., Cronin, J. B., \& Jalilvand, F. (2016). Effect of Different Sprint Training Methods on Sprint Performance Over Various Distances: A Brief Review. Journal of Strength and Conditioning Research, 30(6), 1767-1785

Sarabon, N., Markovic, G., Mikulic, P., \& Latash, M. L. (2013). Bilateral synergies in foot force production tasks. Experimental Brain Research, 227(1), 121-130.

Seethapathi, N., \& Srinivasan, M. (2019). Step-to-step variations in human running reveal how humans run without falling. ELife, 8 .

Sonderegger, K., Tschopp, M., \& Taube, W. (2016). The Challenge of Evaluating the Intensity of Short Actions in Soccer: A New Methodological Approach Using Percentage Acceleration. PloS One, 17(11),

Spasic, M., Krolo, A., Zenic, N., Delextrat, A., \& Sekulic, D. (2015) Reactive Agility Performance in Handball; Development and Evaluation of a Sport-Specific Measurement Protocol. Journal of Sports Science \& Medicine, 14(3), 501-506

Swinton, P. A., Lloyd, R., Keogh, J. W. L., Agouris, I., \& Stewart, A. D. (2014). Regression models of sprint, vertical jump, and change of direction performance. Journal of Strength and Conditioning Research, 28(7), 1839-1848.

Tomáš, M., František, Z., Lucia, M., \& Jaroslav, T. (2014). Profile, correlation and structure of speed in youth elite soccer players. Journal of Human Kinetics, 40, 149-159.
Winter, D. A. (2009). Biomechanics and Motor Control of Human Movement. John Wiley \& Sons.

Yamaguchi, A., Milosevic, M., Sasaki, A., \& Nakazawa, K. (2019) Force Control of Ankle Dorsiflexors in Young Adults: Effects of Bilateral Control and Leg Dominance. Journal of Motor Behavior, 1-10.

Datum prijave: 22.04 .2020 .

Datum prihvatanja: 08.07.2020

\section{Kontakt}

Hasan Ibrić, Doktorand, Fakultet za sport i turizam,

Novi Sad, Radnička 30a

E-mail:hibric@gmail.com

Jernej Rošker, University of Primorska, Faculty of Health Sciences,

Polje 42, Izola, Slovenia

E-mail: jernej.rosker@gmai.com

Živa Majcen Rošker, University of Ljubljana, Faculty of Sport,

Gortanova 22, Ljubljana, Slovenia

E-mail: majcen.ziva10@gmail.com 